\title{
Crónica Seminario Hispano-alemán de Derecho público sobre Instrumentos para superar la crisis de la deuda pública(Baeza, febrero 2012)
}

\author{
Roberto Galán Vioque \\ Profesor Titular de Derecho Administrativo \\ Universidad de Sevilla
}

El pasado día 16 de febrero de 2012 se celebró en Baeza, en la sede de la Universidad Internacional de Andalucía, el Tercer Seminario Hispano-alemán de Derecho público que tuvo en esta ocasión como objeto el estudio de los instrumentos jurídicos habilitados en la Unión Europea para dar respuesta a los graves problemas provocados por el endeudamiento excesivo de algunos países europeos. Este seminario fue organizado por los Profesores Antonio Jiménez-Blanco Carrillo de Albornoz, de la Universidad Politécnica de Madrid, y Christian Pielow, de la Universidad de Bochum. El desarrollo de este seminario fue asumido por los Profesores de Derecho administrativo de la Universidad de Jaén, coordinados por los Profesores José Cuesta Revilla y Antonio Marti del Moral. Asistieron al seminario, aparte de los ponentes, los profesores, de distintas Universidades españolas y alemanas, Lourdes de la Torre Martínez, Mercè Darnaculleta i Gardella, José Esteve Pardo, Jörg Geerlings, Isabelle Heitmann, Rosario Leñero Bohorquez, Christian Schimansky y Marc Tarres Vives, entre otros.

El seminario se inició con unas palabras de salutación dirigidas por los organizadores. En su intervención inicial el Profesor Jiménez-Blanco hizo hincapié en el cambio de paradigma que se está produciendo en el Derecho público como consecuencia de la crisis económica. Por un lado, en el Derecho constitucional se percibe una pérdida de reconocimiento social de la representación parlamentaria, mientras que en el Derecho administrativo la relación tradicional entre la Administración y los administrados/contribuyentes se va progresivamente diluyendo en una relación entre Administración y los acreedores/prestamistas. Y todo ello con la incógnita de si los mecanismos comunitarios creados con la moneda única, el euro, van a ser suficientes para hacer frente a las tensiones financieras actuales. 
A continuación el Profesor Klaus Stern, de la Universidad de Köln, tomó la palabra para presentar las Jornadas. Para este Profesor el Derecho comunitario no estaba preparado para dar respuesta a una situación tan compleja como la provocada por la situación de crisis económica. Pasó a explicar los pasos que se ha habían dado, y se estaban dando, dentro de la Unión Europeas para dar una respuesta conjunta con la aprobación del paquete de seis Directivas sobre déficits excesivos, la creación del eurogrupo para coordinar la política económica y la adopción de medidas de estabilidad para los países con problemas de financiación externa. Con todo, señaló que la estabilidad del propio Euro no está garantizada, lo que exigirá nuevos esfuerzos por parte de los Estados miembros.

La primera ponencia se refiere a la introducción a nivel constitucional, tanto en Alemania como en España, de límites al endeudamiento. Por la parte alemana intervino el Profesor Markus Kaltenborn, de la Universidad de Bochum, quien explicó la reforma constitucional que se realizó en el año 2009 de la Ley Fundamental de Bonn para introducir la obligación del equilibrio presupuestario tanto del Gobierno federal como de los Lánder. Opina que, a pesar de la novedosa regulación de los límites de deficits recogida en los artículo 109 y 115 de la Ley Fundamental, quedan muchos aspectos abiertos que, a su juicio, exigirán un pronunciamiento claro del Tribunal Constitucional alemán, e incluso de una futura nueva reforma constitucional. La réplica a la ponencia alemana corrió a cargo del Profesor Antonio Martí, de la Universidad de Jaén, quien expuso el proceso de reforma constitucional que se ha desarrollado en España en el año 2011 para introducir en el nuevo artículo 135 de la Constitucional un mandato de equilibrio presupuestario aplicable a todas las Administraciones españolas. Reforma que ya se ha reflejado incluso en la propia jurisprudencia del propio Tribunal Constitucional de ese mismo año. Esta reforma constitucional va a suponer que las Administraciones Públicas españolas tengan que valorar en el futuro la viabilidad financiera de todas las políticas que quieren poner en marcha.

La segunda ponencia abordó los nuevos mecanismos de control a nivel de la Unión Europea en relación con el endeudamiento excesivo de los países. El Profesor Albrecht Weber, de la Universidad de Osnabrück, analizó con exhaustividad los distintos instrumentos que ha creado la Unión Europea para hacer frente a las dificultades financieras por las que están pasando un buen número de los países periféricos europeos. Destaca la pérdida de soberanía que experimentan los Estados que tienen que acudir al rescate financiero previsto en la Unión Euroopeo, primero a través del, en siglas inglesas, del EFSM (Fondo Europeo de Estabilidad Financiera) y en el futuro con el ESM (Mecanismo Europeo de Estabilidad). Por parte española, intervinieron los Profesores Francisco Sosa Wag- 
ner y Mercedes Fuertes, ambos de la Universidad de León, quienes se centraron en analizar la tradicional dependencia de la economía española de la financiación externa y en valorar las distintas iniciativas de las Instituciones europeas para intentar salvar la Unión Económica y Monetaria Europea.

Tras la pausa para el almuerzo se adelantó, por necesidades de viaje, la intervención de clausura del Profesor Alfonso Pérez Moreno de la Universidad de Sevilla quien expresó su alegría porque la iniciativa, que se iniciara en Sevilla en 2006, haya conseguido mantener una periodicidad bianual y por el muy cualificado nivel de participación. No esconde las dificultades que plantea la situación actual en Europa, aunque defiende que la respuesta debe venir de la mano del Derecho público.

En el tercer bloque de ponencias se habló sobre las repercusiones que el límite del endeudamiento público tiene sobre el Estado federal alemán y en el autonómico español. El Profesor Winfried Kluth, de la Universidad Halle-Wittenberg, abordó la relación entre la Federación y los Estados federados, destacando cómo los límites al endeudamiento previstos en la Ley fundamental de Bonn vinculan al Gobierno ferderal pero también a los de los Ländern. Presta una especial atención a los supuestos en los que se excepciona la prohibición de endeudarse cuando concuran catástrofes naturales o situaciones de emergencia extraordinarias. Termina disertando sobre las potestades que el Gobierno Federal va a poder ejercer en relación con los Länder cuando incumplan la obligación constitucional del equilibrio presupuestario, lo que ha dado lugar ya a que Schleswig-Holstein haya planteado un conflicto ante el Tribunal Constitucional Federal, que se encuentra pendiente de resolución.

La intervención del Profesor Christian Pielow versó sobre la situación financiera de los Municipios y asociaciones de municipios alemanes. Comienza destacando su mala situación financiera para a continuación analizar el impacto de las normas constitucionales sobre las municipios que en Alemania, como en España, gozan de autonomía. Concluye con la necesidad de que se apruebe un texto legal que establezca con claridad cómo se tiene que aplicar el principio de equilibrio presupuestario a los Municipios y los mecanismos de control que se prevean para los supuestos de incumplimiento. Los Profesores Salvador Martín y José Cuesta, ambos de la Universidad de Jaén, presentan una ponencia en la destacan el efecto centralizador que se está produciendo en España como consecuencia de las medidas legislativas que se está adoptando a nivel estatal para hacer frente a la crisis. Este diagnóstico, que califican de beneficioso, lo hacen a partir de un exhaustivo estudio de los cambios legales que 
se han introducido en materia económica en relación con ámbitos tan delicados como, por ejemplo, la regulación de las cajas de ahorro.

La última sesión tuvo como objeto la conexión entre la supranacionalidad y la crisis del endeudamiento. Inicia esta sesión el Profesor Hermann-Josef Blanke, de la Universidad de Erfurt, quien analiza el impacto del pacto presupuestario, adoptado el 9 de diciembre de 2011 por los países de la zona euro, sobre la estructura de la Unión Europea y también de los Estados Miembros. Parte del fracaso que supuso el Pacto de estabilidad y crecimiento de 1997 y de la insuficiencia de las herramientas previstas en el Tratado de Lisboa, aprobado hace tan solo cinco años. Destaca como los instrumentos de ayuda financiera que se han ido creando en el ámbito de la Unión Europea para ayudar a los Estados con dificultades financieras imponen a su vez a los Estados receptores un compromiso de estabilidad bajo el control de la Comisión europea. La aprobación del citado pacto fiscal, que obliga a los Estados que lo han aceptado a constitucionalizar obligaciones de austeridad fiscal, al mismo tiempo que suponen un paso adelante en el proceso de construcción europea provoca con una notable pérdida de soberanía a los Estados miembros. Lo que paradójicamente no viene acompañado con una simultánea mejora en la legitimidad democrática de las Instituciones comunitarias. Esta circunstancia ha hecho que en Alemania, sobre todo por la posición activa de su Tribunal Constitucional, se exija la necesaria intervención del Bundestag con carácter previo a la adopción de estas decisiones comunitarias de naturaleza financiera.

La posterior intervención de quien firma estas líneas, de la Universidad de Sevilla, se centró en el análisis del pacto fiscal aprobado el 9 de diciembre de 2011 por el grupo ampliado de países de la zona euro con la finalidad de que los Estados asuman ahorros presupuestarios, dispongan de una mayor coordinación de las políticas y de la gobernanza económica y en definitiva se refuercen los instrumentos de estabilización financiera. Se alumbra así una nueva figura, que tiene naturaleza de tratado internacional, denominada Tratado de Estabilidad, Coordinación y Gobernanza de la Unión Económica y Monetaria, que tiene vocación de incorporarse a los Tratados constitutivos.

La última intervención fue la del Profesor Jörg Ennuschat, de la Universidad de Hagen, que expuso la jurisprudencia reciente del Tribunal Constitucional Alemán, ya aludida, en relación con la aprobación por parte de la República Federal de Alemanía de los paquetes europeos de ayuda a países con dificultades de financiación externa que trata de preservar la soberaía fiscal de Alemanía exigiendo la previa aceptación por parte del Bundestag. 
Todas las ponencias dieron a lugar interesantes debates entre los asistentes en los que se pusieron de manifiesto las insuficiencias que presenta el Derecho comunitario actual para preservar la aspiración de una Unión económica y monetaria. Los acontecimientos que se han desarrollado con posterioridad, desgraciadamente, no hacen sino confirmar las conclusiones alcanzadas en este seminario. El sentimiento de que queda mucho por hacer sigue aumentando. No desaparecerá hasta que los Estados miembros sean capaces de hacer una apuesta firme y decidida por la unión económica y monetaria en Europa. 